\title{
Healthcare cost associations of patients who use illicit drugs in Florida: a retrospective analysis
}

Jessica L. Ryan *i( ) and Veronica R. Rosa

\begin{abstract}
Background: Illicit drug use increases visits to the hospital. Research is limited on the costs of these healthcare visits by illicit drug.

Methods: Florida's Agency for Health Care Administration's emergency department and inpatient datasets from 2016 to 2018 were analyzed. Adults who used an illicit drug were included in the study population resulting in 709, 658 observations. Cost-to-charge ratios were used to estimate healthcare costs. Linear regression analyzed associations of illicit drugs with total healthcare cost.

Results: Total healthcare costs are estimated at $\$ 6.4$ billion over the 3 year period. Medicare paid for the most patient care ( $\$ 2.16$ billion) with Medicaid and commercial insurance each estimated at $\$ 1.36$ billion. Cocaine (9.25\%) and multiple drug use (6.12\%) increased the costs of an ED visit compared to a patient with cannabis SUD. Opioids (23.40\%) and inhalants use (16.30\%) increased the costs of inpatient compared to cannabis SUD.

Conclusion: Healthcare costs are high of patients with illicit drug SUD and poisoning, over half of which are paid for with tax payer dollars and to an unknown degree hospital write-offs. Injuries and illness of patients using cocaine and multiple drugs are associated with more expensive ED patient care and opioids and inhalants are associated with more expensive inpatient care.
\end{abstract}

Keywords: Illicit drug use, Healthcare costs, Charge-to-cost ratio, Opioids, Medicare, Medicaid

\section{Introduction}

Nearly half of people have used an illicit drug at least once in their lifetime (National Institute of Drug Abuse [18]. In 2006, opioid-related fatalities were one of the highest causes of injury or death [27]. Between 2006 and 2011, the rates of those diagnosed with opioid addiction nearly tripled [12]. Further, Substance Abuse and Mental Health Services Administration (SAMHSA) found that 56.8 million people were diagnosed with either a substance use disorder (SUD) or mental health condition in

* Correspondence: jryan@uwf.edu

University of West Florida, 11000 University Parkway, Pensacola, FL 32514, USA

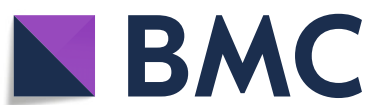

() The Author(s). 2020 Open Access This article is licensed under a Creative Commons Attribution 4.0 International License, which permits use, sharing, adaptation, distribution and reproduction in any medium or format, as long as you give appropriate credit to the original author(s) and the source, provide a link to the Creative Commons licence, and indicate if changes were made. The images or other third party material in this article are included in the article's Creative Commons licence, unless indicated otherwise in a credit line to the material. If material is not included in the article's Creative Commons licence and your intended use is not permitted by statutory regulation or exceeds the permitted use, you will need to obtain permission directly from the copyright holder. To view a copy of this licence, visit http://creativecommons.org/licenses/by/4.0/. The Creative Commons Public Domain Dedication waiver (http://creativecommons.org/publicdomain/zero/1.0/) applies to the data made available in this article, unless otherwise stated in a credit line to the data. 
In the U.S., rates and costs of inpatient stays associated with heroin and opioid overdose grew substantially from 2001 to 2012 [9]. U.S. annual societal costs are estimated at $\$ 740$ billion in overall healthcare spending as well as lost productivity and crime due to all SUD [19]. According to The National Center for Injury Prevention and Control, the misuse of prescription drugs alone costs the nation at least $\$ 78.5$ billion per year [6]. Substance misuse cost an estimated $\$ 1176$ per capita and the full lifetime cost of illicit drug use was estimated at $\$ 43.9$ billion in California in 2010 [16]. Hospital costs have been estimated at $\$ 2783$ (in 2013 dollars) annually per person with a SUD involving illicit substances [8]. It is shown that Medicare recipients with a history of SUD had a mean 6 year cost as much as $\$ 56,178$ more than those without history of SUD [5]. In 2007, Medicare and Medicaid were modified to include reimbursement opportunities to pay for screening and brief intervention for individuals at risk for substance misuse [24].

Medicaid funds more than one third of all substance use disorder treatment in the U.S. [4]. Moving forward, it is expected that expansions to the Patient Protection and Affordable Care Act (ACA) will increase healthcare spending among mental health and substance use disorder services [5]. Substance use prevalence significantly increased among Florida Medicaid recipients and more than tripled among the privately insured between 1999 and 2006 [27]. There is evidence that Medicaid enrollment increases while commercial plan enrollment decreases, following initial overdose for those with SUD [14].

Cocaine, prescription opioids, and heroin were found to be most commonly associated with overdoses [15]. White et al. [27] found that average annual per patient cost was greater for patients specifically using opioids over other substances. Recently, there is a growing trend in synthetic opioids related to overdose deaths [22]. Another study indicated sedatives account for the most intentional overdoses, followed by benzodiazepines such as Xanax and Valium [21]. More than 1 in 4 people using heroin can be expected to have a hospital admission every year [8]. Further research is needed on healthcare use and spending in different SUD user groups [2, 8]. In addition, there is currently not enough standardized cost information for policy makers and funding agencies to use for allocation of support to substance use disorder treatment programs and services $[1,26]$. Some efforts, such as the Florida Brief Intervention and Treatment for Elders (BRITE) project and Screening Brief Intervention and Referral to Treatment (SBIRT), aim to screen and serve individuals at risk for misusing substances [24]. Ideally, these services and referral opportunities may be expanded, updated, and utilized by a wider population. As of March 2020, the National Institute on Drug Abuse (NIDA) was citing a 2007 study as the latest available national cost estimates for illicit drug use [19].

Addiction to illicit drugs can be treated and overdoses and injury prevented [23]. However, this requires not only identifying patients with SUD, but determining the subgroups to target - of particular interest is which populations have the highest healthcare costs. The first objective of this research is to identify the healthcare costs of emergency department (ED) patients and inpatients with illicit drug SUD or overdose in Florida. The second objective of this research is to analyze the associations of healthcare costs of patients with illicit drug SUD or overdose in Florida with demographics, payer, drug type, physical disorders common with SUD, and mental health disorders. The overarching goal of this research is to help researchers further understand the differences in illicit drug use with healthcare costs and to inform policy and decision makers for targeted treatment and allocation of scarce resources.

\section{Methods}

The Florida Agency for Health Care Administration's (AHCA's) ED, inpatient, and financial datasets were used for this research. All datasets are de-identified and available to the public. The ED and inpatient dataset includes demographics, diagnosis codes, length of stay (LOS), and charges. The financial dataset includes each Florida acute care hospital's ownership status as well as total revenues and total expenses. The study population included all ED and inpatients, aged 18 and over, in Florida from 2016 to 2018 who had a principal or other diagnosis code that indicated illicit substance use. International Statistical Classification of Diseases and Related Health Problems Clinical Modification (ICD-10-CM) codes were used to identify patients having a SUD or poisoning (overdose) based on a chart of ICD-10-CM codes of drug abuse by the California Department of Health [3]. The illicit drug categories generally followed ICD-10-CM categories; for example, patients with codes beginning with F12 'cannabis related disorders' or T40 codes related to cannabis poisoning were coded as cannabis users. The drug categories from ICD-10-CM included opioids, cannabis, sedatives, cocaine, stimulants, hallucinogens, and inhalants. If a patient's record indicated they had more than one illicit drug SUD during their visit, they were categorized as using multiple drugs. The initial count for ED observations was 355,758 but 40,614 were missing financial data. The initial count for inpatient observations was 515,559 but 120,720 were missing financial information. The final study population included 709,658 patients: 314,727 ED and 394,841 inpatients. SAS 9.4 and Microsoft Excel were used to analyze the data.

Descriptive statistics as well as two linear regression models were analyzed. The regression models both had total cost as the dependent variable and were analyzed 
with the ED and inpatient datasets separately. Independent variables of the models included demographics, payer, LOS, trauma alert status, physical and mental health comorbidities commonly associated with SUD, drug groups, and hospital factors such as teaching and ownership status. Mental health disorders were controlled for because they have been found to increase the risk of relapse and total healthcare spending for those with SUD $[4,13]$.

Demographics used in the analysis were included in the datasets. Rural designation was based on patient county and the Florida Department of Health's rural classification of counties. Physical and mental comorbidities of the patients were coded based on an ICD-10-CM diagnosis code listing from the Minnesota Department of Human Services [17] and common comorbidities of people with SUD according to SAMHSA [25]. Marijuana was not found to be associated with inpatient stays while other illicit drug SUD were [8]. Therefore, marijuana was used as the reference group in both regression models.

Total healthcare costs were estimated from reported charges by using total hospital cost-to-charge ratios. This method was based off prior research by $\mathrm{Hsu}$ et al. [9]. The cost-to-charge ratios were total patient care services expense divided by total patient care services revenue for each hospital for each year as reported in the AHCA financial datasets. Costs for 2016 and 2017 were then adjusted to 2018 dollars using the hospital producer price index as reported by the Bureau of Labor Statistics. As healthcare charges and costs can skew heavily, the total costs in 2018 dollars for each patient were then log transformed. The total costs in 2018 dollars were used in the descriptive statistics, while the log transformed total cost in 2018 dollars was the dependent variable in the regression models. To interpret the results of the $\log$ transformed cost regression models, the formula " 1 minus exponential to the $x$ " is used to convert the estimates back into real units.

\section{Results}

Demographics by illicit drug type are provided in Table 1 for ED and inpatient visits combined. There were more female inpatients than males for opioids and sedatives use. Hispanic patients had a range of illicit drug use percentages from $7.9 \%$ (stimulants) to $14.5 \%$ (hallucinogens). Black patients had a range of

Table 1 Demographics of ED and Inpatients by Illicit Drug Type in Florida, 2016-2018

\begin{tabular}{|c|c|c|c|c|c|c|c|c|c|c|}
\hline & & Opioids & Sedatives & Cocaine & Stimulants & Hallucinogens & Inhalants & $\begin{array}{l}\text { Multiple } \\
\text { Drugs }\end{array}$ & Cannabis & $\begin{array}{l}\text { Total } \\
\text { Counts }\end{array}$ \\
\hline \multirow[t]{2}{*}{ Gender } & Female & $52.0 \%$ & $54.8 \%$ & $33.0 \%$ & $40.5 \%$ & $24.2 \%$ & $31.0 \%$ & $38.7 \%$ & $38.0 \%$ & 304,815 \\
\hline & Male & $48.0 \%$ & $45.2 \%$ & $67.0 \%$ & $59.5 \%$ & $75.8 \%$ & $69.0 \%$ & $61.3 \%$ & $62.0 \%$ & 405,170 \\
\hline \multirow[t]{2}{*}{ Ethnicity } & Hispanic & $8.5 \%$ & $12.0 \%$ & $13.3 \%$ & $7.9 \%$ & $14.5 \%$ & $10.9 \%$ & $11.1 \%$ & $11.5 \%$ & 74,192 \\
\hline & Non-Hispanic & $91.5 \%$ & $88.0 \%$ & $86.7 \%$ & $92.1 \%$ & $85.5 \%$ & $89.1 \%$ & $88.9 \%$ & $88.5 \%$ & 635,793 \\
\hline \multirow[t]{3}{*}{ Race } & Black & $10.5 \%$ & $6.0 \%$ & $45.2 \%$ & $10.3 \%$ & $23.1 \%$ & $20.8 \%$ & $22.1 \%$ & $34.1 \%$ & 164,808 \\
\hline & Other Race & $4.7 \%$ & $4.7 \%$ & $4.8 \%$ & $5.1 \%$ & $8.6 \%$ & $10.4 \%$ & $4.7 \%$ & $5.8 \%$ & 35,236 \\
\hline & White & $84.8 \%$ & $89.3 \%$ & $50.0 \%$ & $84.6 \%$ & $68.2 \%$ & $68.8 \%$ & $73.2 \%$ & $60.2 \%$ & 509,941 \\
\hline \multirow[t]{5}{*}{ Payer } & Uninsured & $23.7 \%$ & $22.8 \%$ & $37.3 \%$ & $47.7 \%$ & $45.1 \%$ & $37.4 \%$ & $41.6 \%$ & $35.3 \%$ & 232,718 \\
\hline & Medicare & $38.7 \%$ & $35.7 \%$ & $18.9 \%$ & $12.6 \%$ & $7.3 \%$ & $14.7 \%$ & $16.0 \%$ & $13.7 \%$ & 177,106 \\
\hline & Medicaid & $17.6 \%$ & $16.0 \%$ & $28.8 \%$ & $20.4 \%$ & $16.9 \%$ & $20.0 \%$ & $24.0 \%$ & $26.1 \%$ & 159,269 \\
\hline & Other Insurance & $3.9 \%$ & $4.0 \%$ & $5.7 \%$ & $5.6 \%$ & $5.4 \%$ & $8.4 \%$ & $5.7 \%$ & $5.5 \%$ & 34,809 \\
\hline & Commercial & $16.2 \%$ & $21.5 \%$ & $9.3 \%$ & $13.8 \%$ & $25.3 \%$ & $19.5 \%$ & $12.8 \%$ & $19.5 \%$ & 106,083 \\
\hline \multirow{2}{*}{$\begin{array}{l}\text { Trauma } \\
\text { Alert }\end{array}$} & Trauma Alert & $0.4 \%$ & $0.7 \%$ & $0.8 \%$ & $0.8 \%$ & $0.9 \%$ & $3.2 \%$ & $0.7 \%$ & $0.7 \%$ & 4324 \\
\hline & Non Trauma Alert & $99.6 \%$ & $99.3 \%$ & $99.2 \%$ & $99.2 \%$ & $99.1 \%$ & $96.8 \%$ & $99.3 \%$ & $99.3 \%$ & 705,661 \\
\hline \multirow[t]{3}{*}{ Year } & 2016 & $32.6 \%$ & $29.4 \%$ & $30.8 \%$ & $26.1 \%$ & $28.6 \%$ & $45.2 \%$ & $30.2 \%$ & $31.2 \%$ & 221,427 \\
\hline & 2017 & $34.4 \%$ & $31.7 \%$ & $34.0 \%$ & $31.1 \%$ & $31.1 \%$ & $33.5 \%$ & $33.2 \%$ & $33.7 \%$ & 239,691 \\
\hline & 2018 & $32.9 \%$ & $38.9 \%$ & $35.2 \%$ & $42.8 \%$ & $40.4 \%$ & $21.3 \%$ & $36.6 \%$ & $35.1 \%$ & 248,867 \\
\hline \multirow[t]{3}{*}{ Average } & Age (STD) & $\begin{array}{l}49.5 \\
(23.4)\end{array}$ & 49.6 (19.3) & $\begin{array}{l}45.2 \\
(16.0)\end{array}$ & $38.5(22.7)$ & $30.5(24.8)$ & $\begin{array}{l}40.6 \\
(13.9)\end{array}$ & 39.6 (19.0) & $\begin{array}{l}37.0 \\
(18.4)\end{array}$ & \\
\hline & $\begin{array}{l}\text { LOS (inpatients) } \\
\text { (STD) }\end{array}$ & $\begin{array}{l}6.42 \\
(9.9)\end{array}$ & $5.31(7.5)$ & $\begin{array}{l}5.15 \\
(9.5)\end{array}$ & $4.57(9.1)$ & $5.24(14.9)$ & $\begin{array}{l}6.57 \\
(10.5)\end{array}$ & $5.32(9.5)$ & $4.54(6.8)$ & \\
\hline & Total Counts & 267,067 & 17,711 & 133,307 & 38,634 & 2037 & 1406 & 120,759 & 129,064 & 709,985 \\
\hline
\end{tabular}


illicit drug use percentages from $6.0 \%$ (sedatives) to $45.2 \%$ (cocaine). Patients of other races ranged from $4.7 \%$ (opioids, sedatives, and multiple drugs) to $10.4 \%$ (inhalants). White patients with illicit drug use ranged from $50 \%$ (cocaine) to $89.3 \%$ (sedatives). Medicare paid for $38.7 \%$ of all patient visits with SUD of opioids and nearly the same for SUD of sedatives (35.67) while only $7.3 \%$ of stays with SUD of hallucinogens. Medicaid inpatients with SUD ranged from 16.0\% (sedatives) to $28.8 \%$ (cocaine). All patient SUD groups had a trauma alert percentage below 1\%, except for inhalants (3.2\%). Patient visits associated with illicit drug use increased from 2016 to 2018 in every group, except for opioids and inhalants. The total counts of patients by drug group varied greatly from 1406 (inhalants) to 267,067 (opioids).

Healthcare costs from ED and inpatient visits associated with illicit drug use are reported in Table 2. Total costs are estimated at $\$ 6.4$ billion over the three year period. Medicare paid for the most patient care ( $\$ 2.16$ billion) with Medicaid and commercial insurance both around $\$ 1.36$ billion. Uninsured patients accounted for over $\$ 1$ billion in healthcare costs. Patients with an opioid SUD had the greatest total costs at $\$ 2.98$ billion from 2016 to 2018 , followed by cocaine ( $\$ 1.3$ billion), multiple drug users $(\$ 965.2$ million), cannabis (\$764.0 million), stimulants (\$218.6 million), sedatives (\$123.1 million), inhalants (\$11.3 million), and hallucinogens (\$8.7 million). Healthcare costs of patients with cocaine SUD more than doubled from 2017 (\$312.4 million) to 2018 (\$726.8 million).

The results from the ED regression are reported in Table 3. This regression analyzed associations of patients with illicit drug use and their healthcare costs. The independent variables of interest were the illicit drug groups. Cocaine (9.25\%) and multiple drug use (6.12\%) increased the costs of an ED visit compared to a patient with cannabis SUD. Opioids $(-30 \%)$, sedatives $(-19.32 \%)$, stimulants $(-1.84 \%)$, hallucinogens $(-7.9 \%)$, and inhalants $(-13.37 \%)$ all lowered the cost of ED care compared to cannabis. Patients with illicit drug use cost of care increased with Medicare (8.33\%) and other insurance (8.25\%) compared to ED patients with commercial insurance. Uninsured inpatients had lower cost of care by $9.33 \%$ and Medicaid inpatients had costs $1.85 \%$ lower.

The results from the inpatient regression are reported in Table 4. This regression was modeled the same as the ED regression. Opioids $(23.40 \%)$ and inhalants (16.30\%) increased the costs of inpatients compared to cannabis. Sedatives $(-14.80 \%)$, cocaine $(-6.87 \%)$, stimulants (-7.435), hallucinogens (-12.00), and using multiple drugs $(-10.33 \%)$ all lowered healthcare costs compared to cannabis. In addition, having Medicare raised inpatient healthcare costs by $2.85 \%$ compared to patients with commercial insurance. Having Medicaid (-6.77\%), being uninsured (-9.83\%), or having other insurance $(-5.15 \%)$ all lowered healthcare costs compared to commercial patients.

Table 2 Healthcare Costs of Patients by Illicit Drug in Florida, 2016-2018

\begin{tabular}{|c|c|c|c|c|c|c|c|c|c|}
\hline Payer & Opioids & Sedatives & Cocaine & Stimulants & Hallucinogens & Inhalants & $\begin{array}{l}\text { Multiple } \\
\text { Drugs } \\
\end{array}$ & Cannabis & Total Costs \\
\hline Uninsured & $\$ 303,580,273$ & $\$ 12,651,381$ & $\$ 260,645,873$ & $\$ 77,488,376$ & $\$ 3,037,384$ & $\$ 2,090,506$ & $\$ 322,417,982$ & $\begin{array}{l}\$ 206,172, \\
674\end{array}$ & $\begin{array}{l}\$ 1,188,084 \\
449\end{array}$ \\
\hline Medicare & $\begin{array}{l}\$ 1,502,506, \\
095\end{array}$ & $\$ 60,431,863$ & $\$ 207,258,281$ & $\$ 41,906,209$ & $\$ 1,077,986$ & $\$ 2,328,874$ & $\$ 189,335,130$ & $\begin{array}{l}\$ 156,375, \\
886\end{array}$ & $\begin{array}{l}\$ 2,161,220 \\
324\end{array}$ \\
\hline Medicaid & $\$ 514,680,922$ & $\$ 17,562,632$ & $\$ 308,104,203$ & $\$ 52,981,163$ & $\$ 1,996,175$ & $\$ 2,900,562$ & $\$ 271,772,453$ & $\begin{array}{l}\$ 194,873, \\
971\end{array}$ & $\begin{array}{l}\$ 1,364,872, \\
081\end{array}$ \\
\hline $\begin{array}{l}\text { Other } \\
\text { Insurance }\end{array}$ & $\$ 128,885,460$ & $\$ 4,674,212$ & $\$ 60,814,707$ & $\$ 15,463,740$ & $\$ 677,578$ & $\$ 1,670,357$ & $\$ 60,377,110$ & $\$ 53,009,490$ & $\$ 325,572,654$ \\
\hline Commercial & $\$ 534,096,623$ & $\$ 27,738,560$ & $\$ 492,611,678$ & $\$ 30,739,067$ & $\$ 1,904,929$ & $\$ 2,273,589$ & $\$ 121,246,188$ & $\begin{array}{l}\$ 153,570, \\
258\end{array}$ & $\begin{array}{l}\$ 1,364,180, \\
892\end{array}$ \\
\hline \multicolumn{10}{|l|}{ Year } \\
\hline 2016 & $\$ 984,401,523$ & $\$ 35,857,269$ & $\$ 290,192,067$ & $\$ 57,384,749$ & $\$ 2,390,132$ & $\$ 5,472,874$ & $\$ 294,398,297$ & $\begin{array}{l}\$ 246,195, \\
072\end{array}$ & $\begin{array}{l}\$ 1,916,291, \\
983\end{array}$ \\
\hline 2017 & $\$ 991,568,122$ & $\$ 38,220,270$ & $\$ 312,437,040$ & $\$ 67,421,012$ & $\$ 2,945,091$ & $\$ 4,404,895$ & $\$ 319,423,204$ & $\begin{array}{l}\$ 255,874 \\
046\end{array}$ & $\begin{array}{l}\$ 1,992,293, \\
680\end{array}$ \\
\hline 2018 & $\begin{array}{l}\$ 1,007,779 \\
728\end{array}$ & $\$ 48,981,109$ & $\$ 726,805,635$ & $\$ 93,772,794$ & $\$ 3,358,829$ & $\$ 1,386,119$ & $\$ 351,327,362$ & $\begin{array}{l}\$ 261,933, \\
161\end{array}$ & $\begin{array}{l}\$ 2,495,344 \\
737\end{array}$ \\
\hline Total Costs & $\begin{array}{l}\$ 2,983,749 \\
373\end{array}$ & $\begin{array}{l}\$ 123,058, \\
648\end{array}$ & $\begin{array}{l}\$ 1,329,434, \\
742\end{array}$ & $\begin{array}{l}\$ 218,578, \\
555\end{array}$ & $\$ 8,694,052$ & $\begin{array}{l}\$ 11,263 \\
888\end{array}$ & $\$ 965,148,863$ & $\begin{array}{l}\$ 764,002 \\
279\end{array}$ & $\begin{array}{l}\$ 6,403,930 \\
400\end{array}$ \\
\hline
\end{tabular}


Table 3 Regression Model of Healthcare Costs of ED Patients with Illicit Drug SUD

\begin{tabular}{|c|c|c|c|c|c|}
\hline Column1 & Variable & Parameter Estimate & Standard Error & $\operatorname{Pr}>|t|$ & $\%$ Change to Cost \\
\hline & Intercept & 6.8428 & 0.0062 & $<.0001$ & \\
\hline \multirow[t]{2}{*}{ Gender } & Female $^{a}$ & 0.0554 & 0.0034 & $<.0001$ & $5.69 \%$ \\
\hline & Male (ref.) & - & - & - & \\
\hline Age & $\mathrm{Age}^{\mathrm{a}}$ & 0.0034 & 0.0001 & $<.0001$ & $0.34 \%$ \\
\hline \multirow[t]{2}{*}{ Ethnicity } & Hispanic $^{a}$ & 0.0634 & 0.0056 & $<.0001$ & $6.55 \%$ \\
\hline & Non-Hispanic (ref.) & - & - & - & \\
\hline \multirow[t]{3}{*}{ Race } & Black & 0.0046 & 0.0043 & 0.2773 & \\
\hline & Other $^{a}$ & 0.0376 & 0.0078 & $<.0001$ & $3.83 \%$ \\
\hline & White (reference) & - & - & - & \\
\hline \multirow[t]{2}{*}{ Rural } & Rural $^{\mathrm{a}}$ & 0.0771 & 0.0085 & $<.0001$ & $8.01 \%$ \\
\hline & Urban (ref.) & - & - & - & \\
\hline \multirow[t]{5}{*}{ Payer } & Uninsured $^{a}$ & -0.098 & 0.0049 & $<.0001$ & $-9.33 \%$ \\
\hline & Medicare $^{a}$ & 0.08 & 0.0063 & $<.0001$ & $8.33 \%$ \\
\hline & Medicaid $^{\mathrm{a}}$ & -0.0187 & 0.0055 & 0.0007 & $-1.85 \%$ \\
\hline & Other $^{a}$ & 0.0793 & 0.0087 & $<.0001$ & $8.25 \%$ \\
\hline & Commercial (ref.) & - & - & - & \\
\hline LOS & $\operatorname{LOS}^{a}$ & 0.559 & 0.0023 & $<.0001$ & $74.90 \%$ \\
\hline \multirow[t]{2}{*}{ Trauma Alert } & Trauma Alert $^{\mathrm{a}}$ & 1.668 & 0.0398 & $<.0001$ & $430.16 \%$ \\
\hline & Non-Trauma Alert (ref.) & - & - & - & \\
\hline \multirow[t]{4}{*}{ Physical Comorbidities } & Liver Disease $^{a}$ & 0.3739 & 0.0161 & $<.0001$ & $45.34 \%$ \\
\hline & Severe Liver Disease ${ }^{a}$ & 0.4058 & 0.0970 & $<.0001$ & $50.05 \%$ \\
\hline & HIV/AIDS & -0.0083 & 0.0193 & 0.6675 & \\
\hline & None (ref.) & - & - & - & \\
\hline \multirow[t]{9}{*}{ Mental Comorbidities } & Anxiety ${ }^{a}$ & 0.1225 & 0.0057 & $<.0001$ & $13.03 \%$ \\
\hline & Mood & 0.0455 & 0.0279 & 0.1024 & \\
\hline & Schizophrenia and Personality ${ }^{a}$ & -0.1118 & 0.0087 & $<.0001$ & $-10.58 \%$ \\
\hline & Bipolar $^{a}$ & 0.0308 & 0.0083 & 0.0002 & $3.13 \%$ \\
\hline & Depression $^{a}$ & 0.0418 & 0.0067 & $<.0001$ & $4.27 \%$ \\
\hline & Conduct & -0.0245 & 0.0463 & 0.5962 & \\
\hline & PTSD $^{a}$ & -0.028 & 0.0137 & 0.0402 & $-2.77 \%$ \\
\hline & $\mathrm{ADHD}^{\mathrm{a}}$ & -0.0807 & 0.0187 & $<.0001$ & $-7.76 \%$ \\
\hline & None (ref.) & - & - & - & \\
\hline \multirow[t]{8}{*}{ Drugs } & Opioids $^{a}$ & -0.3567 & 0.0047 & $<.0001$ & $-30.00 \%$ \\
\hline & Sedatives $^{a}$ & -0.2146 & 0.0108 & $<.0001$ & $-19.32 \%$ \\
\hline & Cocaine $^{a}$ & 0.0885 & 0.0051 & $<.0001$ & $9.25 \%$ \\
\hline & Stimulants ${ }^{a}$ & -0.0186 & 0.0072 & 0.0096 & $-1.84 \%$ \\
\hline & Hallucinogens $s^{\mathrm{a}}$ & -0.0823 & 0.0250 & 0.001 & $-7.90 \%$ \\
\hline & Inhalants $^{\mathrm{a}}$ & -0.1435 & 0.0316 & $<.0001$ & $-13.37 \%$ \\
\hline & Multiple Drugs $^{a}$ & 0.0594 & 0.0058 & $<.0001$ & $6.12 \%$ \\
\hline & Cannabis (ref.) & - & - & - & \\
\hline
\end{tabular}


Table 3 Regression Model of Healthcare Costs of ED Patients with Illicit Drug SUD (Continued)

\begin{tabular}{|c|c|c|c|c|c|}
\hline Column1 & Variable & Parameter Estimate & Standard Error & $\operatorname{Pr}>|t|$ & $\%$ Change to Cost \\
\hline \multirow[t]{2}{*}{ Teaching Hospital } & Teaching $^{a}$ & -0.2618 & 0.0059 & $<.0001$ & $-23.03 \%$ \\
\hline & Non-Teaching (ref.) & - & - & - & \\
\hline \multirow[t]{3}{*}{ Hospital Ownership } & For-Profit ${ }^{a}$ & 0.0830 & 0.0038 & $<.0001$ & $8.65 \%$ \\
\hline & Government $^{\mathrm{a}}$ & -0.2420 & 0.0049 & $<.0001$ & $-21.49 \%$ \\
\hline & Not-For-Profit (ref.) & - & - & - & \\
\hline
\end{tabular}

${ }^{a}$ statistically significant at the $a=0.05$ level

\section{Discussion}

There were fewer observations from the ED dataset than the inpatient dataset for patients with illicit drug use. With other disease and injury research, there are usually greater observations in the ED because a small percentage of those get admitted. Patients with illicit drug use who seek care from a hospital appear to have a high admittance rate, which implies their injuries/illnesses are severe. Counts and healthcare costs of patients with an illicit drug SUD or poisoning in their records increased each year in Florida from 2016 to 2018. Either drug use is increasing in Florida or the people who use illicit drugs are getting injured or sick at a higher rate. In total, illicit drug use cost $\$ 6,403,930,400$ over 3 years of which over half $(\$ 3,526,092,405)$ was paid from public insurance. Uninsured patients cost $\$ 1$, $188,084,449$ in patient visits; it is unknown from the dataset how much of this the hospitals will write off as charity care or bad debt. The total costs of healthcare associated with illicit drug use are much higher as this study did not include ambulatory care or rehabilitation costs. Although, it is clear illicit drugs cost the healthcare system a large amount of money each year. As policy makers have limited resources for the prevention and treatment of illicit drug use, the second objective of this research was to identify associations of illicit drugs with cost.

All illicit drug groups were found to be statistically associated with healthcare costs compared to cannabis. Interestingly though, only cocaine and multiple drugs were associated with higher ED costs and only opioids and inhalants were associated with higher inpatient costs. Sedatives, stimulants, and hallucinogens were all associated with lower healthcare costs than cannabis when demographics, physical and mental comorbidities, and hospital factors were controlled. In Florida, the opioid group had the most patients and the highest costs from 2016 to 2018, which is not surprising considering the current epidemic the country is experiencing. Inpatients who used inhalants were shown to have a greater percentage of trauma alerts and average longer LOS, which would indicate a greater severity of injury.
This may explain why inpatient costs would be higher for this group.

There are limitations to this study. One, the data includes Florida hospitals and may not be indicative of the rest of the country. Secondly, cost estimates are used as the datasets only have charges reported. However, the estimates of healthcare costs should be conservative as over 160,000 observations were not included due to missing data. In addition, some SUD may not be reported during hospital visits. Since the datasets are deidentified, patients are not tracked over time. The 394, 841 inpatient observations are probably not unique users, as it is likely that people with illicit drug SUD are admitted more than once. This may bias the results if groups who use certain illicit drugs frequent the ED and hospital more often. Additionally, there may be an implication for the statistical testing if the observations are not independent.

\section{Conclusion}

Illicit drug use can devastate families. It places an extra burden on the police, court system, prisons, hospitals, EMS, and social workers, to name a few. Additionally, it affects everyone financially. Healthcare costs are high of patients with illicit drug SUD and poisoning, over half of which are paid for with tax payer dollars and to an unknown degree hospital write-offs. Injuries and illness of patients using cocaine and multiple drugs are associated with more expensive ED care and opioids and inhalants are associated with more expensive inpatient care. Prevention and treatment programs for people who use cocaine, inhalants, opioids, and multiple drugs could potentially pay for themselves in terms of healthcare costs averted. Particularly, the data provided shows how much Medicare and Medicaid is spending on healthcare costs of patients with illicit drug use. This research may help those who conduct cost benefit analyses or cost effectiveness analyses for substance use disorder programs.

Further research should include the total costs of healthcare associated with illicit drug use in ambulatory care. In addition, future research may help 
Table 4 Regression Model of Healthcare Costs of Inpatients with Illicit Drug SUD

\begin{tabular}{|c|c|c|c|c|c|}
\hline & Variable & Parameter Estimate & Standard Error & $\operatorname{Pr}>|t|$ & $\%$ Change to Cost \\
\hline & Intercept & 8.3235 & 0.0059 & $<.0001$ & \\
\hline \multirow[t]{2}{*}{ Gender } & Female & -0.0005 & 0.0027 & 0.8552 & \\
\hline & Male (ref.) & - & - & - & \\
\hline Age & $\mathrm{Age}^{\mathrm{a}}$ & 0.0067 & 0.0001 & $<.0001$ & $0.68 \%$ \\
\hline \multirow[t]{2}{*}{ Ethnicity } & Hispanic $^{a}$ & -0.0250 & 0.0046 & $<.0001$ & $-2.47 \%$ \\
\hline & Non-Hispanic (ref.) & - & - & - & \\
\hline \multirow[t]{3}{*}{ Race } & Black $^{a}$ & -0.0394 & 0.0034 & $<.0001$ & $-3.87 \%$ \\
\hline & Other $^{a}$ & 0.1217 & 0.0064 & $<.0001$ & $12.94 \%$ \\
\hline & White (ref.) & - & - & - & \\
\hline \multirow[t]{2}{*}{ Rural } & Rural & -0.0075 & 0.0070 & 0.2864 & \\
\hline & Urban (ref.) & - & - & - & \\
\hline \multirow[t]{5}{*}{ Payer } & Uninsured $^{\mathrm{a}}$ & -0.1035 & 0.0044 & $<.0001$ & $-9.83 \%$ \\
\hline & Medicare $^{a}$ & 0.0281 & 0.0043 & $<.0001$ & $2.85 \%$ \\
\hline & Medicaid $^{a}$ & -0.0701 & 0.0044 & $<.0001$ & $-6.77 \%$ \\
\hline & Other Insurance ${ }^{a}$ & -0.0529 & 0.0067 & $<.0001$ & $-5.15 \%$ \\
\hline & Commercial (ref.) & - & - & - & \\
\hline LOS & $\operatorname{LOS}^{\mathrm{a}}$ & 0.0501 & 0.0001 & $<.0001$ & $5.14 \%$ \\
\hline \multirow[t]{2}{*}{ Trauma Alert } & Trauma Alert $^{\mathrm{a}}$ & 1.1036 & 0.0133 & $<.0001$ & $201.51 \%$ \\
\hline & Non-Trauma Alert (ref.) & - & - & - & \\
\hline \multirow[t]{4}{*}{ Physical Comorbidities } & Liver Disease $^{a}$ & 0.1868 & 0.0052 & $<.0001$ & $20.54 \%$ \\
\hline & Severe Liver Disease $^{\mathrm{a}}$ & 0.2642 & 0.0145 & $<.0001$ & $30.23 \%$ \\
\hline & HIV/AIDS ${ }^{a}$ & 0.1325 & 0.0108 & $<.0001$ & $14.17 \%$ \\
\hline & None (ref.) & - & - & - & \\
\hline \multirow[t]{9}{*}{ Mental Comorbidities } & Anxiety & -0.0023 & 0.0031 & 0.4604 & \\
\hline & Mood $^{\mathrm{a}}$ & -0.1366 & 0.0110 & $<.0001$ & $-12.77 \%$ \\
\hline & Schizophrenia and Personality ${ }^{a}$ & -0.2184 & 0.0050 & $<.0001$ & $-19.62 \%$ \\
\hline & Bipolar $^{\mathrm{a}}$ & 0.0993 & 0.0050 & $<.0001$ & $10.43 \%$ \\
\hline & Depression $^{\mathrm{a}}$ & 0.0555 & 0.0035 & $<.0001$ & $5.71 \%$ \\
\hline & Conduct $^{\mathrm{a}}$ & -0.4158 & 0.0286 & $<.0001$ & $-34.02 \%$ \\
\hline & PTSD $^{a}$ & -0.1844 & 0.0057 & $<.0001$ & $-16.84 \%$ \\
\hline & $\mathrm{ADHD}^{\mathrm{a}}$ & -0.1264 & 0.0102 & $<.0001$ & $-11.87 \%$ \\
\hline & None (ref.) & - & - & - & \\
\hline \multirow[t]{8}{*}{ Drugs } & Opioids ${ }^{\mathrm{a}}$ & 0.2103 & 0.0042 & $<.0001$ & $23.40 \%$ \\
\hline & Sedatives $^{\mathrm{a}}$ & -0.1602 & 0.0091 & $<.0001$ & $-14.80 \%$ \\
\hline & Cocaine $^{a}$ & -0.0711 & 0.0047 & $<.0001$ & $-6.87 \%$ \\
\hline & Stimulants ${ }^{\mathrm{a}}$ & -0.0772 & 0.0072 & $<.0001$ & $-7.43 \%$ \\
\hline & Hallucinogens ${ }^{a}$ & -0.1279 & 0.0313 & $<.0001$ & $-12.00 \%$ \\
\hline & Inhalants ${ }^{\mathrm{a}}$ & 0.1510 & 0.0345 & $<.0001$ & $16.30 \%$ \\
\hline & Multiple Drugs $^{\mathrm{a}}$ & -0.1090 & 0.0045 & $<.0001$ & $-10.33 \%$ \\
\hline & Cannabis (ref.) & - & - & - & \\
\hline \multirow[t]{2}{*}{ Teaching Hospital } & Teaching $^{a}$ & 0.1632 & 0.0045 & $<.0001$ & $17.73 \%$ \\
\hline & Non-Teaching (ref.) & - & - & - & \\
\hline \multirow[t]{3}{*}{ Hospital Ownership } & For-Profit ${ }^{a}$ & 0.0149 & 0.0029 & $<.0001$ & $14.96 \%$ \\
\hline & Government $^{\mathrm{a}}$ & -0.0957 & 0.0042 & $<.0001$ & $-9.13 \%$ \\
\hline & Not-For-Profit (ref.) & - & - & - & \\
\hline
\end{tabular}


explain why cocaine inpatient healthcare costs more than doubled in 1 year but did not have the corresponding increase in counts.

\section{Abbreviations}

AHCA: Agency for Health Care Administration; ADHD : Attention deficit hyperactivity disorder; ED : Emergency department; ICD-10-CM: International Statistical Classification of Diseases and Related Health Problems Clinical Modification; LOS : Length of stay; NIDA: National Institute on Drug Abuse; ACA: Patient Protection and Affordable Care Act; PTSD: Post-traumatic stress disorder; SAMHSA: Substance Abuse and Mental Health Services Administration; SUD: Substance use disorder

\section{Acknowledgements}

$\mathrm{N} / \mathrm{A}$

\section{Authors' contributions}

$J L R$ and VRR designed the research study. JLR analyzed the data while VRR was a major contributor in writing the manuscript. Both authors read and approved the final manuscript

\section{Authors' information}

$J L R$ is a clinical assistant professor at the University of West Florida and routinely analyzes healthcare costs in Florida. VRR is a MAT counselor.

\section{Funding}

There was no funding for this research.

\section{Availability of data and materials}

The datasets generated and/or analysed during the current study are available in the Agency for Healthcare Administration repository, [https:// www.floridahealthfinder.gov/researchers/orderdata/order-data.aspx]

\section{Ethics approval and consent to participate}

N/A

\section{Consent for publication}

N/A

\section{Competing interests}

The authors declare that they have no competing interests.

Received: 20 May 2020 Accepted: 3 September 2020

Published online: 29 September 2020

\section{References}

1. Alexandre PK, Beulaygue IC, French MT, McCollister KE, Popovici I, Sayed BA. The economic cost of substance abuse treatment in the state of Florida. Eval Rev. 2012;36(3):167-85.

2. Birnbaum HG, White AG, Schiller M, Waldman T, Cleveland JM, Roland CL Societal costs of prescription opioid abuse, dependence, and misuse in the United States. Pain Med. 2011;12(4):657-67.

3. California Department of Public Health. Epicenter Alcohol/Drug Consequences Query: Categories and ICD Codes Used. 2014. https://www. cdph.ca.gov/Programs/CCDPHP/DCDIC/SACB/CDPH\%20Document\%2 OLibrary/EpiCenter/AOD-ICD-Coding-070315.pdf. Accessed 4 Feb 2020.

4. Clark RE, Baxter JD, Aweh G, O'Connell E, Fisher WH, Barton BA. Risk factors for relapse and higher costs among Medicaid members with opioid dependence or abuse: opioid agonists, comorbidities, and treatment history. J Subst Abus Treat. 2015;57:75-80.

5. Fairman BJ, Hwang S, Alexandre PK, Gallo JJ, Eaton WW. Costs of substance use disorders from claims data for Medicare recipients from a populationbased sample. J Subst Abus Treat. 2017. https://doi.org/10.1016/j.jsat.2017. 02.007 .

6. Florence CS, Zhou C, Luo F, Xu L. The economic burden of prescription opioid overdose, abuse, and dependence in the United States, 2013. Med Care. 2016. https://doi.org/10.1097/MLR.0000000000000625.

7. Graham K, Cheng J, Bernards S, Wells S, Rehm J, Kurdyak P. How much do mental health and substance use/addiction affect use of general medical services? Extent of use, reason for use, and associated costs. Can J Psychiatr. 2017. https://doi.org/10.1177/0706743716664884.
8. Gryczynski J, Schwartz RP, O'Grady KE, Restivo L, Mitchell SG, Jaffe JH. Understanding patterns of high-cost health care use across different substance user groups. Health Aff. 2016;35(1):12-9.

9. Hsu DJ, McCarthy EP, Stevens JP, Mukamal KJ. Hospitalizations, costs and outcomes associated with heroin and prescription opioid overdoses in the United States 2001-12. Addiction. 2017;112(9):1558-64.

10. Jakovljevic MB, Jovanovic M, Lesch OM. Accessiblity and affordability of alcohol dependency medical care in Serbia. Front Psychiatry. 2014. https:// doi.org/10.3389/fpsyt.2014.00192

11. Kamal R, Cox C, Rousseau D. Costs and outcomes of mental health and substance use disorders in the US. JAMA. 2017. https://doi.org/10.1001/jama. 2017.8558.

12. Kirson NY, Shei A, Rice JB, Enloe CJ, Bodnar K, Birnbaum HG, et al. The burden of undiagnosed opioid abuse among commercially insured individuals. Pain Med. 2015;16(7):1325-32.

13. Lin W, Bharel M, Zhang J, O'Connell E, Clark RE. Frequent emergency department visits and hospitalizations among homeless people with Medicaid: implications for Medicaid expansion. Am J Public Health. 2015; 105:S716-22.

14. Maeng DD, Han JJ, Fitzpatrick MH, Boscarino JA. Patterns of health care utilization and cost before and after opioid overdose: findings from 10-year longitudinal health plan claims data. Subst Abus Rehabil. 2017:8:57.

15. Martins SS, Sampson L, Cerda M, Galea S. Worldwide prevalence and trends in unintentional drug overdose: a systematic review of the literature. Am J Public Health. 2015. https://doi.org/10.2105/AJPH.2015.302843.

16. Miller TR, Nygaard P, Gaidus A, Grube JW, Ponicki WR, Lawrence BA, et al. Heterogeneous costs of alcohol and drug problems across cities and counties in California. Alcohol Clin Exp Res. 2017;41(4):758-68.

17. Minnesota Department of Human Services. ICD-10 mental health billable diagnosis codes in alphabetical order by description. 2017. https://www.dhs. state.mn.us/main/groups/agencywide/documents/pub/dhs16_197744.pdf. Accessed 5 Feb 2020.

18. National Survey of Drug Use and Health. National Institute on Drug Abuse (NIDA)a. 2020. https://www.drugabuse.gov/drug-topics/trends-statistics/ national-drug-early-warning-system-ndews/national-survey-drug-use-health Accessed 3 Apr 2020.

19. Drug Abuse Trends and Statistics. NIDAb. 2020. https://www.drugabuse.gov/ drug-topics/trends-statistics\#supplemental-references-for-economic-costs. Accessed 3 Apr 2020.

20. Otterstatter MC, Crabtree A, Dbrer S, Kinniburgh B, Klar S, Leamon A, et al. Patterns of health care utilization among people who overdosed from illegal drugs: a descriptive analysis using the BC provincial overdose cohort. Health Promot Chron. 2018;38(9):328-33.

21. Rooney BL, Voter MT, Eberlein CM, Schossow AJ, Fischer CL. Mapping drug overdose demographic and socioeconomic characteristics in the community. WMJ. 2018;117(1):18-23.

22. Ropero-Miller JD, Speaker PJ. The hidden costs of the opioid crisis and the implications for financial management in the public sector. Forensic Sci Int: Synergy. 2019;1:227-38.

23. Rosenberg L. Surgeon General's report on addiction: what does it mean? J Behav Health Ser R. 2017. https://doi.org/10.1007/s11414-016-9544-5.

24. Schonfeld L, King-Kallimanis BL, Duchene DM, Etheridge RL, Herrara JR, Barry $\mathrm{KL}$, et al. Screening and brief intervention of substance misuse among older adults: The Florida BRITE project. Am J Public Health. 2010;100(1):108-14.

25. Substance Abuse and Mental Health Services Administration. Common comorbidities 2019. https://www.samhsa.gov/medication-assistedtreatment/treatment/common-comorbidities. Accessed 5 Feb 2020.

26. United States Government Accountability Office. Research on health care costs of untreated conditions is limited. GAO-19-274. 2019.

27. White AG, Birnbaum HG, Schiller M, Waldman T, Cleveland JM, Roland CL. Economic impact of opioid abuse, dependence, and misuse. AM J Pharm Benefits. 2011;3:e59-70.

\section{Publisher's Note}

Springer Nature remains neutral with regard to jurisdictional claims in published maps and institutional affiliations. 